\title{
Reference Ranges of Serum Blood Urea Nitrogen, Creatinine Concentration and Ultrasonographic Measurement of the Kidneys in Term Healthy Newborns in the Neonatal Period
}

\author{
Şebnem KADER', Mehmet MUTLU1, Elif BAHAT ÖZDOĞAN², Yakup ASLAN', İlker EYÜPOĞLU, \\ Ayşegül CANSU ${ }^{3}$, Mehmet SARIAYDIN 1 , Yüksel Ali YAZICIOĞLU ${ }^{4}$
}

Trabzon, Turkey

\begin{abstract}
OBJECTIVE: Acute kidney injury is an important problem in neonates. We conducted a cross-sectional prospective study to determine normal serum blood urea nitrogen, creatinine reference ranges and ranges of ultrasonographic measurement of kidneys in healthy term newborns.
\end{abstract}

STUDY DESIGN: Blood samples were collected from total 357 healthy newborns at birth $(n=45), 1^{\text {st }}$ $(n=30), 3^{\text {rd }}(n=61), 7^{\text {th }}(n=34), 10^{\text {th }}(n=132), 14^{\text {th }}(n=36)$, and $28^{\text {th }}(n=19)$ days of life. Renal ultrasonographic was performed by the same two radiologists on 81 newborns aged 10 days.

RESULTS: Serum blood urea nitrogen and creatinine concentrations have reached to the highest level at the first day of life and have returned to cord level at the third day of life. There were gradually decrease in serum blood urea nitrogen and creatinine levels after the first day of life. There were significant difference in both right and left renal length, width, and volumes in terms of gender and these parameters were statistically higher in boys than girls $(p<0.05)$. Birth weight of the boys $(3548 \pm 539 \mathrm{~g})$ was statistically higher than girls $(3307 \pm 405 \mathrm{~g})(p=0.028)$. There was a positive correlation between birth weight and right $(r=0.38, p=0.000)$ and left kidney volumes $(r=0.44, p=0.000)$.

CONCLUSION: Our findings showed that measured blood urea nitrogen and creatinine levels changed in accordance with postnatal days and there was a positive correlation between kidney volume and birth weight of newborns. We concluded that these findings are important for evaluation of acute kidney injury and for screening of for urinary tract anomalies in neonates.

Keywords: Blood urea nitrogen, Creatinine, Newborn, Ultrasonography, Kidney

Gynecol Obstet Reprod Med 2017;23(3):163-168

\author{
${ }^{1}$ Division of Neonatology, ${ }^{2}$ Pediatric Nephrology, ${ }^{3}$ Department of \\ Radiology, \\ ${ }^{4}$ Department of Biochemistry Karadeniz Technical University Faculty of \\ Medicine, Trabzon \\ Address of Correspondence: Mehmet Mutlu \\ Department of Pediatrics, Division of \\ Neonatology, Karadeniz Technical \\ University Faculty of Medicine \\ Trabzon, Turkey \\ Submitted for Publication: $\quad 22.03 .2017$ \\ Accepted for Publication: $\quad 22.07 .2017$
}

\begin{tabular}{|c|c|}
\hline & Access this article online \\
\hline $\begin{array}{c}\text { Quick Response Code: } \\
\text { 品e }\end{array}$ & Website: www.gorm.com.tr \\
\cline { 2 - 2 } & DOI:10.201613/GORM.2017.693 \\
\hline & \\
\hline
\end{tabular}

How to cite this article: Kader Ş. Mutlu M. Bahat Özdoğan E. Aslan Y. Eyüpoğlu İ. Cansu A. Sarıaydın M. Yazıcıoğlu YA. Reference Ranges of Serum Blood Urea Nitrogen. Creatinine Concentration and Ultrasonographic Measurement of the Kidneys in Term Healthy Newborns in the Neonatal Period. Gynecol Obstet Reprod Med 2017;23(3):163-168

\section{Introduction}

Acute kidney injury (AKI) is characterized by the abrupt inability of the kidneys to adequately excrete waste products and regulate fluid and electrolyte homeostasis appropriately. Decline in the glomerular filtration rate leads to a usually reversible increase in the blood concentration of creatinine $(\mathrm{Cr})$ and nitrogenous waste products levels and generally it is presented with a decrease in the urine output. So that it becomes an important contributing factor to the morbidity and mortality of critically ill neonates (1).

Acute kidney injury in the newborn is an important problem and $8-24 \%$ of the neonates admitted to neonatal intensive care unit have AKI (2). Developmental immaturity that limits the function of the immature kidney, hemodynamic changes like hypotension and hypoxia at birth and in the early neonatal period, an increased risk of hypovolemia due to large insensible water losses during the first days of life make newborns, especially preterms, more susceptible to renal failure. 
Early diagnosis of neonatal renal pathology is extremely important for newborns to prevent or delay kidney injury. Renal functional tests and ultrasonography (USG) were commonly used for neonatal renal pathology. USG is a noninvasive imaging modality that can be used for assessment of renal diseases or congenital renal anomalies in neonate. Serum blood urea nitrogen (BUN) and $\mathrm{Cr}$ concentration may be changed in the neonatal period. Knowledge of reference ranges for normal serum $\mathrm{BUN}, \mathrm{Cr}$ concentration and normal renal parameters determined with USG is essential for the accurate evaluation of renal diseases or anomalies. Although serum BUN and $\mathrm{Cr}$ values in infants with very low birth weight during their first days of life are frequently studied, knowledge about BUN and Cr values in term newborns is limited (3). This study was undertaken to determine ranges of ultrasonographic measurement of kidneys and both of normal serum BUN, Cr reference ranges in healthy term newborns on cord blood and $1^{\text {st }}, 3^{\text {rd }}, 7^{\text {th }}, 10^{\text {th }}, 14^{\text {th }}, 28^{\text {th }}$ days of life.

\section{Material and Method}

This cross-sectional prospective study was carried out in 357 healthy term newborns, from June 2008 to December 2013. Inclusion criteria were (i) an Apgar score of $\geq 7$ at $1^{\text {st }}$ and $5^{\text {th }}$ minutes of life for newborns (ii) 37-42 weeks' gestation (iii) appropriate height, weight and head circumference for gestational age, (iv) having no history of renal pathology in utero fetal USG and (v) mothers having no history of renal disease and having normal BUN and $\mathrm{Cr}$ level.

Newborns with any congenital malformation or suspected syndrome, intrauterine growth retardation or any suspicion of systemic disease, weighing $<2.5 \mathrm{~kg}$, patients with hyperbilirubinemia, hypertriglyceridemia and hypernatremic dehydration or neonates with weight loss more than $10 \%$ of birth weight in the first week of life and samples with hemolysis were excluded. Birth weight, gestational age (GA), height, head circumference, gender, delivery type, Apgar scores, weight of newborns on $1^{\text {st }}, 3^{\text {rd }}, 7^{\text {th }}, 10^{\text {th }}, 14^{\text {th }}$ and $28^{\text {th }}$ days of their life, maternal BUN and $\mathrm{Cr}$ levels before delivery were recorded.

Blood samples were collected from 357 healthy newborns at birth (cord; n: 45) and on the $1^{\text {st }}(\mathrm{n}: 30), 3^{\text {rd }}$ (n: 61), $7^{\text {th }}$ (n: $34), 10^{\text {th }}(\mathrm{n}: 132), 14^{\text {th }}(\mathrm{n}: 36)$ and $28^{\text {th }}(\mathrm{n}: 19)$ days of life. Mixed cord blood samples from both the umbilical artery and vein were obtained. Venous blood samples were obtained for the other days.

Serum was separated according to standard procedures and stored at $-80^{\circ} \mathrm{C}$ until analyzed. Concentrations of BUN [manufacturer's reference limits for infants ( $<1$ year): 4-19 mg/dL] and $\mathrm{Cr}$ (manufacturer's reference limits for term neonate: $0.24-$ $0.85 \mathrm{mg} / \mathrm{dL}$ ) were measured using commercial kits (Roche Diagnostics GmbH, Mannheim, Germany) by kinetic enzymatic method and the kinetic Jaffé method respectively, on a The Hitachi modular system auto analyzer (Tokyo, Japan).
Renal USG was performed by the same two radiologists on 81 newborns aged 10 days. Siemens Acuson Antares ultrasonography and a $\mathrm{C} 5-2 \mathrm{MHz}$ convex probe were used for the measurement. Maximum length (L) width (W) and depth (D) were measured on both sides for calculating kidney volume. The kidney volume was calculated using the ellipsoid volume formula as $\mathrm{L} \times \mathrm{W} \times \mathrm{D} \times 0.523(4,5)$. Anteroposterior (AP) diameter of the renal pelvis and parenchymal thickness were also measured. Ethical approval and written informed consent were obtained from parents.

\section{Statistical analysis}

The descriptive statistical analysis was performed for all the studied variables. SPSS 21.0 was used to analyze and data obtained by measurements are given as means \pm standard deviation (SD), medians, $2.5^{\text {th }}, 10^{\text {th }}, 90^{\text {th }}$ and $97.5^{\text {th }}$ percentiles. The data obtained in measurements of the normal distribution were analyzed using the Kolmogorov-Smirnov test. Data in conformity with normal distribution were analyzed using Students t-test, and those not conforming to normal distribution using the Mann Whitney U-test. Pearson's or Spearman Correlation test was used for correlation. The results of the analysis are presented as $\mathrm{p}$-values, $\mathrm{p}<0.05$ was regarded as statistically significant.

\section{Results}

This study was carried out in 357 term healthy newborns. Blood samples were obtained from 357 newborns. USG evaluation was performed on 81 (61\%) of 132 blood taken patients on the 10th day of life. Mean birth weight, height and head circumference of all newborns were $3539 \pm 554 \mathrm{~g}, 50.0 \pm 1.5 \mathrm{~cm}$, and $34.9 \pm 0.8 \mathrm{~cm}$, respectively. Forty-eight percent of these newborns $(n=173)$ were female. Sixty-two percent of newborns $(n=223)$ were born through vaginal deliveries.

Percentiles $(2.5,10,90,97.5)$, mean \pm standard deviation and median values of BUN $(\mathrm{mg} / \mathrm{dL})$ and $\mathrm{Cr}(\mathrm{mg} / \mathrm{dL})$ in neonatal period are shown in table 1 and table 2, respectively. Maternal BUN and $\mathrm{Cr}$ level were $10.6 \pm 3.4$ (5-18) and $0.45 \pm 0.16(0.03-0.68)$, respectively. There were no statistically difference between maternal BUN, $\mathrm{Cr}$ concentrations and cord BUN, Cr concentrations ( $p>0.05$ ). There was an increase at the first day of life and then gradually decrease in serum BUN and $\mathrm{Cr}$ levels after the first day of life. Serum BUN and Cr concentrations have reached to the highest level at the first day of life and returned to cord level on the third day of life.

There was no statistically significant difference between males and females in terms of serum BUN and $\mathrm{Cr}$ levels $(p>0.05)$. There were also no statistically significant difference between levels of serum BUN and $\mathrm{Cr}$ among newborns delivered by Caesarian section and those delivered vaginally both in cord and first day taken blood samples, respectively $(\mathrm{p}>0.05)$. In newborns delivered by Caesarian section, cord levels of BUN and Cr were 10.0 \pm 3.2 (4.8-16.2) and 0.46 \pm 0.2 
(0.05-0.73); first day taken BUN and $\mathrm{Cr}$ levels were 13.0 \pm 5.1 (4.8-21.5) and $0.6 \pm 0.3$ (0.1-1.12). In newborns delivered vaginally, cord levels of BUN and Cr were 9.2 2.2 (4.4-14.6) and $0.4 \pm 0.12$ (0.02-0.68); first day taken BUN and $\mathrm{Cr}$ levels were $12.8 \pm 3.9(4.4-19.5)$ and $0.56 \pm 0.2(0.07-1)$.

Renal USG was performed on $23 \%(n=81)$ of all newborns and $46 \%(n=37)$ of these were female. There were no significant difference between girls and boys in terms of gestational age, head circumference and length of newborns assessed by USG. But birth weight was statistically higher in boys $(3548 \pm 539 \mathrm{~g})$ than girls $(3307 \pm 405 \mathrm{~g})(\mathrm{p}=0.028)$. Median val- ues, 2.5, 10, 90, 97.5 percentiles and mean \pm SD (minimummaximum) and p-values of kidneys' length, width, depth, volume, parenchymal thickness and AP pelvic diameter of the kidneys according to gender were shown in table 3 and 4 . There were significant difference in both right and left renal length, width, and volumes in terms of gender and these parameters were statistically higher in boys than girls $(p<0.05)$ (Table 4). There was no significant difference in renal depth, parenchymal thickness and anterior posterior pelvic diameter in terms of gender between right and left kidneys $(p>0.05)$ (Table 4).

Table 1: Percentiles, median and Mean $\pm S D$ values of BUN ( $\mathrm{mg} / \mathrm{dL})$

\begin{tabular}{lccccccc} 
Age & $\mathrm{n}$ & $2.5^{\text {th }}$ & $10^{\text {th }}$ & Median & $90^{\text {th }}$ & $97.5^{\text {th }}$ & Mean \pm SD \\
\hline Cord & 45 & 4.6 & 6.0 & 9.2 & 13.8 & 15.8 & $9.6 \pm 2.7(4.4-16.2)$ \\
$1^{\text {st }}$ day & 30 & 4.4 & 6.7 & 12.3 & 20.1 & 21.5 & $12.9 \pm 4.5(4.4-21.5)$ \\
$3^{\text {rd }}$ day & 61 & 3.0 & 4.3 & 10.2 & 23.7 & 34.4 & $11.3 \pm 7.4(3.0-34.4)$ \\
$7^{\text {th }}$ day & 34 & 2.7 & 3.1 & 6.2 & 16.3 & 23.1 & $8.0 \pm 4.9(2.7-23.1)$ \\
$10^{\text {th }}$ day & 132 & 3.1 & 4.2 & 7.4 & 10.5 & 12.7 & $7.2 \pm 2.3(2.9-13.8)$ \\
$14^{\text {th }}$ day & 36 & 2.5 & 3.2 & 6.8 & 13.4 & 17.3 & $7.6 \pm 3.6(2.5-17.6)$ \\
$28^{\text {th }}$ day & 19 & 2.3 & 3.3 & 6.8 & 10.0 & 12.0 & $6.7 \pm 2.5(2.3-12)$ \\
\hline
\end{tabular}

* To convert from milligrams per deciliter ( $\mathrm{mg} / \mathrm{dl})$ of blood urea nitrogen to micromoles per liter ( $\mu$ mol/l), multiply by 0.357

Table 2: Percentiles, median and Mean $\pm S D$ values of $\mathrm{Cr}(\mathrm{mg} / \mathrm{dL})$ in neonatal period

\begin{tabular}{llllllll}
\hline Age & $\mathrm{n}$ & $2.5^{\text {th }}$ & $10^{\text {th }}$ & median & $90^{\text {th }}$ & $97.5^{\text {th }}$ & Mean $\pm S D$ \\
\hline Cord & 45 & 0.03 & 0.27 & 0.44 & 0.64 & 0.72 & $0.43 \pm 0.15(0.02-0.73)$ \\
$1^{\text {st }}$ day & 30 & 0.07 & 0.33 & 0.54 & 0.92 & 1.11 & $0.58 \pm 0.24(0.07-1.12)$ \\
$3^{\text {rd }}$ day & 61 & 0.02 & 0.07 & 0.35 & 0.72 & 0.84 & $0.36 \pm 0.25(0.01-0.85)$ \\
$7^{\text {th }}$ day & 34 & 0.03 & 0.07 & 0.27 & 0.48 & 0.49 & $0.25 \pm 0.15(0.03-0.50)$ \\
$10^{\text {th }}$ day & 132 & 0.02 & 0.10 & 0.28 & 0.42 & 0.50 & $0.26 \pm 0.13(0.02-0.51)$ \\
$14^{\text {th }}$ day & 36 & 0.02 & 0.06 & 0.21 & 0.45 & 0.74 & $0.24 \pm 0.16(0.02-0.77)$ \\
$28^{\text {th }}$ day & 19 & 0.05 & 0.07 & 0.10 & 0.25 & 0.28 & $0.12 \pm 0.06(0.05-0.29)$ \\
\hline
\end{tabular}

** To convert from milligrams per deciliter $(\mathrm{mg} / \mathrm{dL})$ of creatinine to micromoles per liter $(\mu \mathrm{mol} / \mathrm{L})$, multiply by 88.4

Table 3: Percentiles of ultrasonographic measurements of renal parameters according to gender

\begin{tabular}{|c|c|c|c|c|c|c|c|c|c|c|}
\hline & \multicolumn{5}{|c|}{ Male } & \multicolumn{5}{|c|}{ Female } \\
\hline & $2.5^{\text {th }}$ & $10^{\text {th }}$ & Median & $90^{\text {th }}$ & $97.5^{\text {th }}$ & $2.5^{\text {th }}$ & $10^{\text {th }}$ & Median & $90^{\text {th }}$ & $97.5^{\text {th }}$ \\
\hline Right renal length $(\mathrm{mm})$ & 36.9 & 39.1 & 45.9 & 52.0 & 57.6 & 33.7 & 39.0 & 43.1 & 48.0 & 49.0 \\
\hline Right renal width (mm) & 18.1 & 20.0 & 25.0 & 30 & 33.3 & 19 & 19.8 & 23.6 & 27.3 & 32 \\
\hline Right renal depth (mm) & 11.5 & 17.0 & 22.0 & 26.5 & 27.9 & 13.4 & 15.6 & 21 & 24.3 & 28.3 \\
\hline Right volume $\left(\mathrm{cm}^{3}\right)$ & 7.1 & 9 & 13.1 & 18.4 & 19.9 & 5.9 & 8.3 & 10.8 & 15.0 & 19.7 \\
\hline Right parenchymal thickness $(\mathrm{mm})$ & 5.7 & 6.3 & 7.4 & 10.3 & 13.1 & 6.2 & 6.4 & 7.7 & 9.5 & 9.9 \\
\hline Right A-P pelvic diameter $(\mathrm{mm})$ & 0 & 0 & 1.0 & 4.7 & 4.8 & 0 & 0 & 1.1 & 2.6 & 3.0 \\
\hline Left renal length (mm) & 37.0 & 41.0 & 48.0 & 52.0 & 56.5 & 24.1 & 38.5 & 44.0 & 48.2 & 50.9 \\
\hline Left renal width $(\mathrm{mm})$ & 17.4 & 21.5 & 25.0 & 28.4 & 31.0 & 17.0 & 19.5 & 24.1 & 26.4 & 28.0 \\
\hline Left renal depth (mm) & 15.1 & 17.5 & 21.0 & 25.6 & 28.6 & 14.0 & 15.8 & 20.0 & 23.3 & 38.8 \\
\hline Left volume $\left(\mathrm{cm}^{3}\right)$ & 8.0 & 9.1 & 13.5 & 18.5 & 20.2 & 6.3 & 8.4 & 11.5 & 13.5 & 15.9 \\
\hline Left parenchymal thickness $(\mathrm{mm})$ & 6.2 & 6.4 & 7.8 & 10.8 & 13.4 & 5.9 & 6.9 & 8.0 & 9.9 & 11.9 \\
\hline Left A-P pelvic diameter (mm) & 0 & 0 & 1.65 & 4.5 & 4.8 & 0 & 0 & 1.9 & 4.0 & 4.7 \\
\hline
\end{tabular}

A-P: Anterior posterior 
Table 4: $P$ values and Mean $\pm S D$ values of ultrasonographic measurements of renal parameters according to gender

\begin{tabular}{|c|c|c|c|}
\hline & $\begin{array}{c}\text { Male } \\
\text { Mean } \pm S D(\text { min-max })\end{array}$ & $\begin{array}{c}\text { Female } \\
\text { Mean } \pm S D(\text { min-max })\end{array}$ & $p$ \\
\hline Right renal length (mm) & $45.4 \pm 4.9(36.8-58)$ & $43.3 \pm 3.4(33.7-49)$ & 0.036 \\
\hline Right renal width (mm) & $25.2 \pm 3.5(18-33)$ & $23.6 \pm 2.8(19-32)$ & 0.037 \\
\hline Right renal depth (mm) & $21.7 \pm 3.1(15-28)$ & $20.9 \pm 2.9(14-28)$ & 0.26 \\
\hline Right volume $\left(\mathrm{cm}^{3}\right)$ & $13.3 \pm 4.0(6.7-23.3)$ & $11.5 \pm 2.8(5.7-20.4)$ & 0.018 \\
\hline Right parenchymal thickness (mm) & $8.0 \pm 1.6(5.7-13.2)$ & $7.8 \pm 1.1(6.2-9.9)$ & 0.78 \\
\hline Right A-P pelvic diameter (mm) & $1.9 \pm 1.4(0-4.8)$ & $1.4 \pm 0.7(0-3)$ & 0.71 \\
\hline Left renal length (mm) & $47.1 \pm 4.6(36.7-59)$ & $44.2 \pm 3.3(37.9-51)$ & 0.01 \\
\hline Left renal width (mm) & $25.1 \pm 2.5(17-31)$ & $23.5 \pm 2.7(17-28)$ & 0.016 \\
\hline Left renal depth (mm) & $21.2 \pm 3.0(15-28.8)$ & $19.9 \pm 2.5(14-25.6)$ & 0.37 \\
\hline Left volume $\left(\mathrm{cm}^{3}\right)$ & $13.4 \pm 3.2(7-20)$ & $10.9 \pm 2.3(6.2-16.2)$ & 0.001 \\
\hline Left parenchymal thickness (mm) & $8.2 \pm 1.7(6.2-13.5)$ & $8.0 \pm 1.3(5.9-12.1)$ & 0.81 \\
\hline Left A-P pelvic diameter (mm) & $2.2 \pm 1.5(0-4.8)$ & $1.8 \pm 1.2(0-4.7)$ & 0.81 \\
\hline
\end{tabular}

A-P: Anterior posterior

There were a positive correlation between birth weight of newborns and right kidney length $(\mathrm{r}=0.38, \mathrm{p}=0.000)$, left kidney length $(\mathrm{r}=0.27, \mathrm{p}=0.012)$, right kidney depth $(\mathrm{r}=0.32$, $\mathrm{p}=0.003)$, right kidney width $(\mathrm{r}=0.28, \mathrm{p}=0.009)$, left kidney width $(\mathrm{r}=0.30, \mathrm{p}=0.008)$, right kidney volumes $(\mathrm{r}=0.38$, $\mathrm{p}=0.000)$ and left kidney volumes $(\mathrm{r}=0.44, \mathrm{p}=0.000)$. There was no significant correlation between height and kidney parameters on each sides.

\section{Discussion}

Early diagnosis of neonatal renal pathology is extremely important for prevention or treatment of the renal diseases. If these pathologies are not early detected and subsequently managed, many of these abnormalities would manifest later in life as pyelonephritis, hypertension, or even end-stage renal failure. Kidney size, renal parenchymal thickness and renal pelvis size are important for recognition of obstructive renal disease associated with hydronephrosis and including congenital renal anomalies such as polycystic kidney diseases. Determination of nitrogen degradation products is very substantial for diagnosis of AKI in newborn since approximately half of AKI in newborns may go non-oliguric. This article defines measurements of kidneys of healthy newborns in the neonatal period.

Newborns are considered to have AKI if the plasma $\mathrm{Cr}$ is more than $1.5 \mathrm{mg} / \mathrm{dL}$ for at least 24 to 48 hours while mother's renal function is normal or with an increase in serum $\mathrm{Cr}$ by 0.3 $\mathrm{mg} / \mathrm{dl} /$ day and/or plasma BUN $\geq 20 \mathrm{mg} / \mathrm{dL}(2,6-10)$. In our study, the serum $\mathrm{Cr}$ and BUN levels at birth were similar to the concentration of their mothers. BUN and $\mathrm{Cr}$ levels have reached to the highest level at 24 hours of life. After then BUN and $\mathrm{Cr}$ levels have gradually decreased to cord levels at the 3 rd days of life. This aspect of our study, contributes to the evaluation of AKI in the neonatal period because of indicating the reference range of plasma BUN and $\mathrm{Cr}$ according to postnatal ages.

Median cord serum $\mathrm{Cr}$ concentration is almost equivalent to the maternal level (11), as in our results. Neonatal serum $\mathrm{Cr}$ initially reflects maternal values and then decreases over subsequent weeks after birth at different rates depending on gestational age. Pottel et al. (12) reported that an increase in serum $\mathrm{Cr}$ level on the first days of life. Boer et al. (13) showed that a rapid decline of serum $\mathrm{Cr}$ during the first weeks of life. Median cord serum $\mathrm{Cr}$ concentration was given by Boer et al. (13) as $0.62 \mathrm{mg} / \mathrm{dL}$ and by Pottel et al. (12) as $0.75 \mathrm{mg} / \mathrm{dL}$. The median serum $\mathrm{Cr}$ concentration at 28 days is given as 0.28 $\mathrm{mg} / \mathrm{dL}$ by Boer et al. (13) and as $0.30 \mathrm{mg} / \mathrm{dL}$ by Pottel et al. (12). Serum $\mathrm{Cr}$ concentrations were found to be lower in our study as $0.44 \mathrm{mg} / \mathrm{dL}$ for the median at birth and as $0.10 \mathrm{mg} / \mathrm{dL}$ for the median at 28 days. It could be related to the serum $\mathrm{Cr}$ assay used or ethnicity.

Subramanian et al. (14) reported that serum $\mathrm{Cr}$ fails to fall below maternal plasma Cr within 5-7 days. Gallini et al. (15) showed that serum $\mathrm{Cr}$ level gradually increased until the fourth day of life in neonates with GA $<28$ weeks and there was also an increase at the first day of life in neonates with GA 28-32 weeks. There is a strong inversely correlation between serum $\mathrm{Cr}$ and GA in the first 48 hours of life. Serum Cr concentration rises dramatically in the first 48 hours of life in premature infants with GA 23-35 weeks (16). Sudden cessation of the maternal clearance, low glomerular filtration rate, maternal $\mathrm{Cr}$ load on $\mathrm{Cr}$ concentration, low tubular clearance of $\mathrm{Cr}$, passive back-diffusion of $\mathrm{Cr}$ concentration can increase the serum $\mathrm{Cr}$ levels in newborns at the first days of life (11, 13). We have shown an increase in serum $\mathrm{Cr}$ concentrations at the $1^{\text {st }}$ day of life, serum $\mathrm{Cr}$ concentrations decreased to cord level at the $3^{\text {rd }}$ day of life, after than a gradually decrease was observed in the neonatal period in term infants. 
After birth, there is a fluid contraction in the extra cellular fluid (ECF). Atrial natriuretic peptide plays a role in the post natal contraction of the ECF (17). A high value of BUN can result from catabolism, dehydration, high protein load or renal failure (11). Dehydration can cause an increase in serum BUN level on the first day of life. Serum BUN levels have returned to cord levels at the third day of life. After then serum $\mathrm{Cr}$ and BUN levels have gradually decreased in the neonatal period.

With the increase in the use of antenatal sonography, fetal renal abnormalities such as hydronephrosis, cystic renal disease have been detected more frequently. Normal parameters are required for determination of abnormal kidneys. In this study, we measured normal parameters of the kidneys and investigated whether there are significant differences in the sonographic characteristics of the kidney in male and female neonates. Yamazaki et al. (18) reported that kidney longitudinal length and largest area were significantly greater in males on each side. Adeyekun et al. (19) reported that total renal volume and renal length showed significant correlation with weight and height, but they concluded that neonatal renal size are independent from gender and race. Soyupak et al. (20) showed that there was positive correlation between weight, height and abdominal organ size. In our study, there was significant difference in both right and left renal length, width, and volumes in terms of gender and these parameters were statistically higher in boys than girls. In our cases, renal volume, renal length, width showed significant correlation with birth weight. These differences should be considered when sonography is done for screening for urinary tract anomalies in newborns. But we have not determined significant correlation between height and kidney parameters on each side.

Anteroposterior diameter of the renal pelvis is important for the evaluation of hydronephrosis. Leung et al. reported that the maximum AP diameter of the renal pelvis on either right or left sides of all fetuses with 37 gestational age ranged from 0.1 to $6.3 \mathrm{~mm}$ (male: $2.69 \pm 0.93 \mathrm{~mm}$ and female: $2.46 \pm 0.87$ $\mathrm{mm}$ ) and male fetuses were found to have greater AP diameter of renal pelvis than female (21). In our study, AP diameter of the renal pelvis was on either right $1.2 \pm 1.2(0-4.8) \mathrm{mm}$ and on left sides $1.9 \pm 1.5(0-4.9) \mathrm{mm}$. But we did not find significant difference between male and female in terms of AP diameter of the renal pelvis.

Fetal hydronephrosis is a common finding on antenatal ultrasound examination occurring in 0.5 to 1 percent of pregnancies (22). Although hydronephrosis is a transient, physiologic state in most cases, urinary tract obstruction such as ureteropelvic junction obstruction, posterior urethral valves and vesicoureteral reflux can occasionally be causal. Lee et al. (23) reported that 36 percent of patients with antenatal hydronephrosis have renal/urinary tract abnormalities in postnatal evaluation. Measurement of the maximum AP diameter of the renal pelvis in the transverse plane is the most generally accepted method to define hydronephrosis. There is no consensus on the threshold AP diameter of the renal pelvis that defines clinically significant antenatal hydronephrosis that necessitates postnatal follow-up and has a high likelihood for renal pathology.

We conclude that our results can suggest a significant contribution to the evaluation of newborns with AKI and renal abnormalities such as antenatal hydronephrosis. Our results have shown that measured BUN and Cr levels change according to postnatal days. There is a strong correlation between kidney volume and birth weight of newborn babies. Ultrasonographic parameters of the kidney vary in terms of gender. These differences should be considered when sonography is done for screening for urinary tract anomalies in newborns.

This study provides a satisfactory evalution for serum BUN, Cr concentration and ultrasonographic measurement of the kidneys in term healthy newborns in the neonatal period. But the weakness of our study is the inability to perform USG for all blood taken patients. Besides, serial blood measurement could not be made from same patients. The strength of our study is the frequent measurement of BUN and $\mathrm{Cr}$ values in the neonatal period and assesment of both USG and serum BUN, Cr concentration. Further studies in a larger collective are needed.

\section{References}

1. Andreoli SP. Acute kidney injury in children. Pediatr Nephrol 2009;24(2):253-63.

2. Gouyon JB, Guignard JP. Management of acute renal failure in newborns. Pediatr Nephrol 2000;14(10-11):103744.

3. Fanaroff AA, Martin RJ. Diseases of the fetus and infant. $9^{\text {th }}$ edition. St Louis, Missouri.Mosby, 2011.1818.

4. Babcock D. Pediatric Kidneys, Atlas of ultrasound measurements. 2nd edition. Philadelphia: Mosby, 2006:270.

5. Griffith CJ, Murray A, Ramsden PD. Accuracy andrepeatability of bladder volume measurement using ultrasonic imaging. J Urol 1986;136(4):808-12.

6. Mathur NB, Agarwal HS, Maria A. Acute renal failure in neonatal sepsis. Indian J Pediatr 2006;73(6):499-502.

7. Agras PI, Tarcan A, Baskin E, Cengiz N, Gürakan B, Saatci U. Acute renal failure in the neonatal period. Ren Fail 2004;26(3):305-9.

8. Aggarwal A, Kumar P, Chowdhary G, Majumdar S, Narang A. Evaluation of renal functions in asphyxiated newborns. J Trop Pediatr 2005;51(5):295-9.

9. Norman ME, Asadi FK. A prospective study of acute renal failure in the newborn infant. Pediatrics 1979;63(3):475-9.

10. Askenazi DJ, Ambalavanan N, Goldstein SL. Acute kidney injury in critically ill newborns: what do we know? What do we need to learn? Pediatr Nephrol 2009;24(2): 
$265-74$.

11. Nafday SM, Brion LP, Benchimol C, Satlin LM, Flynn JT, Chester CM. Avery's Neonatology: Pathophysiology and management of the newborn. $6^{\text {th }}$ edition. Philadelphia: Lippincott Williams \& Wilkins, 2005;981-1065.

12. Pottel H, Vrydags N, Mahieu B, Vandewynckele E, Croes K, Martens F. Establishing age/sex related serum creatinine reference intervals from hospital laboratory data based on different statistical methods. Clin Chim Acta 2008; 396(1-2): 49-55.

13. Boer DP, de Rijke YB, Hop WC, Cransberg K, Dorresteijn EM. Reference values for serum creatinine in children younger than 1 year of age. Pediatr Nephrol 2010; 25(10): 2107-13.

14. Subramanian S, Agarwal R, Deorari AK, Paul VK, Bagga A. Acute renal failure in neonates. Indian J Pediatr 2008; 75(4): 385-91.

15. Gallini F, Maggio L, Romagnoli C, Marrocco G, Tortorolo G. Progression of renal function in preterm neonates with gestational age $<$ or $=32$ weeks. Pediatr Nephrol 2000; 15(1-2):119-24.

16. Miall LS, Henderson MJ, Turner AJ, Brownlee KG, Brocklebank JT, Newell SJ, et al. Plasma creatinine rises dramatically in the first 48 hours of life in preterm infants. Pediatrics 1999;104(6):76.
17. Modi N, Bétrémieux P, Midgley J, Hartnoll G. Postnatal weight loss and contraction of the extracellular compartment is triggered by atrial natriuretic peptide. Early Hum Dev 2000;59(3):201-8.

18. Yamazaki Y, Yago R, Toma H. Sonographic characteristics of the urinary tract in healthy neonates. J Urol 2001; 166(3):1054-57.

19. Adeyekun AA, Ibadin MO, Omoigberale AI. Ultrasound assessment of renal size in healthy term neonates: a report from Benin City, Nigeria. Saudi J Kidney Dis Transpl 2007;18(2):277-81.

20. Soyupak SK, Narli N, Yapicioğlu H, Satar M, Aksungur EH. Sonographic measurements of the liver, spleen and kidney dimensions in the healthy term and preterm newborns. Eur J Radiol 2002;43(1):73-8.

21. Leung VYF, Chu WCW, Metrewel C. Prenatal ultrasound study of gender difference in urinary tract morphology in normal fetuses. HK J Paediatr 2008;13(3):165-70.

22. Blyth B, Snyder HM, Duckett JW. Antenatal diagnosis and subsequent management of hydronephrosis. J Urol 1993;149(4):693.

23. Lee RS, Cendron M, Kinnamon DD, Nguyen HT. Antenatal hydronephrosis as a predictor of postnatal outcome: a meta-analysis. Pediatrics 2006;118(2):586. 